\title{
Graduate Overschooling: Measurement Issues and the Nigeria Situation
}

\author{
Nsisong A. Udoh*, Eme U. Joseph, Ijeoma J. Amajuoyi \\ Department of Educational Foundations, Guidance and Counselling, University of Uyo, Uyo, Nigeria \\ *Corresponding Author: nsisong99@yahoo.com
}

Copyright (C) 2014 Horizon Research Publishing All rights reserved.

\begin{abstract}
This paper provides a brief account of contemporary issues in overschooling. The main emphasis is on theoretical and measurement approaches to graduate overschooling. The paper draws on four models (the neoclassical account, Spence's Job-Screening Model, Thurow's Job-Competition Model, and Beck's Human Capital Theory) to explain the measures of overschooling, job-skill match and wage equilibrium on both the short run and the long run. The paper further assesses, based on literature from industrial psychology, how overschooling with attendant job dissatisfaction can result in adverse workplace behaviour with attendant counter-productivity. The paper then presents a prevue of the overschooling situation in Nigeria before it concludes with extensive recommendations for public and private policy makers, educators, economists, and education investors.
\end{abstract}

Keywords Overschooling, Measures, Theories, Nigerian Graduates

\section{Introduction}

To the average person, no one could possibly overschool. This notion could be shared by many for a variety of reasons ranging from the well-known fact that no knowledge acquired is waste to the truism that learning is a continuum. The issue of overschooling however is not just a mere notion shared by scholars in labour economics and education but a reality. Besides, if one may invoke common sense, one could conjecture that insofar as underschooling is real, overschooling is equally existent. Several studies on the economics of education have sought to understand and explain this phenomenon. Before proceeding to analyse the findings of a few such studies, a cursory look at the defining features of overschooling would be useful.

In defining overschooling, existing professional literature usually draws on these three criteria: (1) a decline in the economic position of educated individuals relative to historically higher levels (2) under fulfilled expectations of the educated with respect to their occupational attainments (3) the possession by workers of greater educational skills than their jobs require [1]. In the light of these defining pointers, it becomes clear that overschooling is a real phenomenon that has without doubt increased its reach over time. This is especially so when we consider the fact that in the past decades, with the proliferation of academic institutions, educational attainment is on the increase with emphasis on university education. On the other hand, estimated rates of employment are rather too slow to accommodate the multitude of educated persons churned into the labour market annually. Even more worrisome is the fact that the bulk of available employment occur at the clerical cadre and lower level service occupations. As a result of these factors, graduates are forced into jobs that are incommensurate with their level of educational attainment. The results usually obtained in the end does not always preclude job dissatisfaction and such unethical corporate behaviours as absenteeism from work, noncompliance to directives from super-ordinates especially when the later are educationally subordinate to them. Cumulatively, productivity bears the brunt leading to economic crisis for institutions and nations.

This paper hopes to provide a fore gleam of the graduate overschooling situation in Nigeria by taking an x-ray of global issues in overschooling whilst furnishing a sound understanding of the concept and measures of graduate overschooling. The paper will therefore proceed with a theoretical explanation of the overschooling phenomenon followed by an assessment of the possibility of overschooling in Nigeria before it concludes and proffers strategies for assessment, evaluation, and containment of overschooling in Nigeria.

\section{Theoretical Approaches to Overschooling}

In the research literature, there are at least four well known and widely accepted models in the explanation of overschooling. These models are the neoclassical model, Spence's Job-screening model, Thurow's Job-competition 
model, and Becker's Human capital model.

\subsection{The Neoclassical Model}

According to neoclassical economists, production input is directly proportional to production cost. This implies that insofar as firms will always adapt their production processes to minimize production cost, a change in the relative supply of labour (labour being one of the major factors of productions) will result in a new equilibrium set of wages (See Fig 1). Thus, given flexible production process and zero adjustment cost, production process can be redesigned to take advantage of the cheaper and more abundant skilled labour. In the same vein, given flexible educational processes and zero adjustment cost, that is, if an additional investment in education brings lower returns than alternatives and unrealized occupational expectations, an individual will reformulate his investment plan and expectations. The outcome of these expectations by firms and individuals in the long run is that the skills of workers will be fully utilized and their expectations fulfilled.

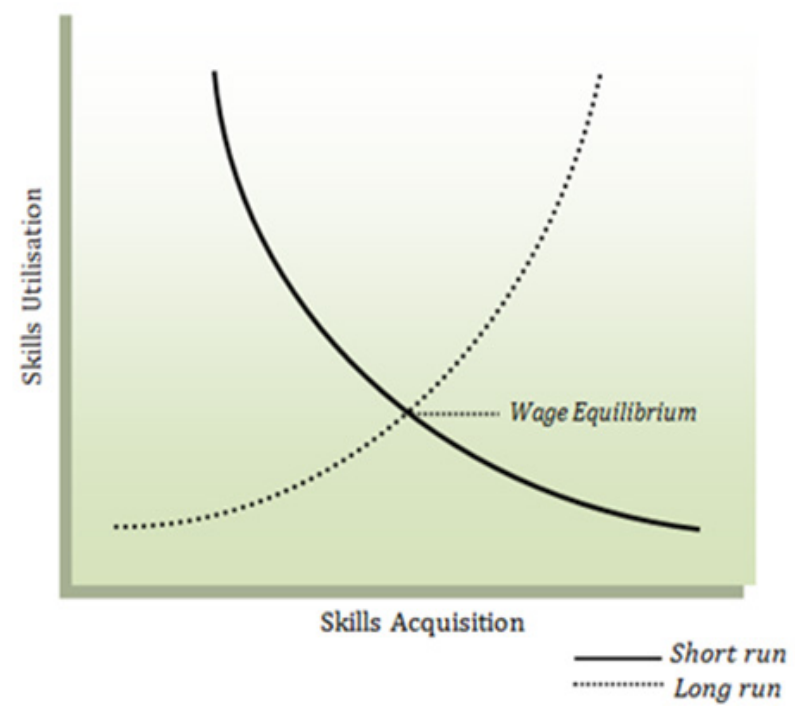

Figure 1. An illustration of the Neoclassical Model

In sum, neoclassical economists see overschooling as a short run problem in the labour market when there is only a temporary mismatch between supply of and demand for educated workers. If the neoclassical position on production processes and adjustment cost remains constant, firms will be able to adjust quickly to the labour market disequilibrium occasioned by overschooling thus making overschooling a sort run problem. Otherwise, the long run maximum utilization of acquired education will turn out to be too long with implications for labour life cycle.

\subsection{Spence's Job-screening Model}

According to Spence's [2[ Job-Screening Model, the labour market is characterized by imperfect information and education is used as a signal to identify more able and motivated individuals or those that would be more productive to employers. Thus, to acquire more of the signal, individuals will continue to invest in education with the expectation that an additional amount of educational signal suffices to distinguish them from others in the labour market. Thus, this model postulates that a rise in educational attainment is directly proportional to a rise in job requirements if such requirements remain constant (See Fig. 2). Ceteris paribus, the private return from educational investment is directly proportional to investment in education otherwise the incidence of overschooling.

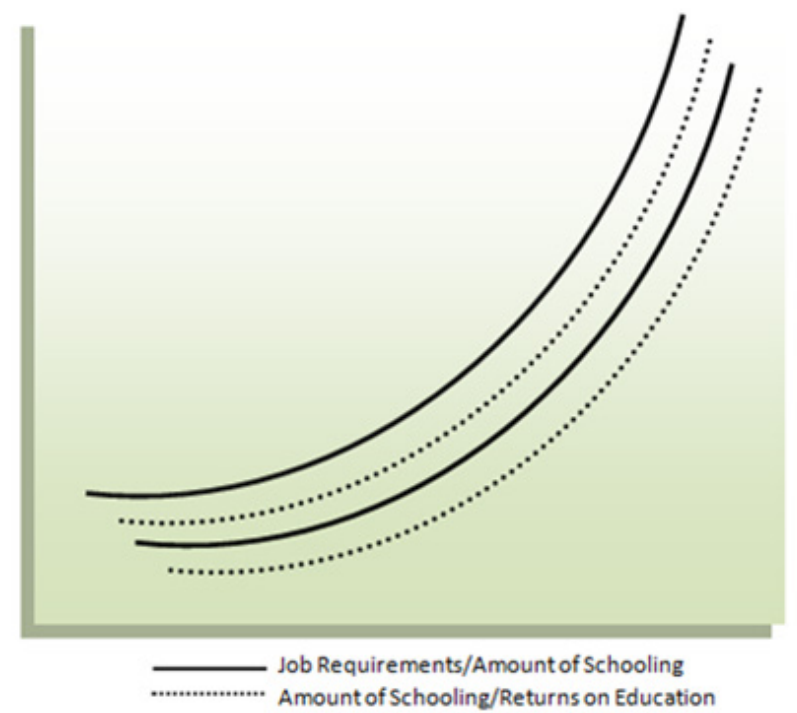

Figure 2. An illustration of Spence's Job-Screening Model

\subsection{Thurow's Job-Competition Model}

Thurow [3], in his job-competition model considers two queues: a job queue and a person queue. In the job queue, every job has its peculiar skill requirement, productivity characteristics, and pay scale. In the individual queue, every individual in the queue is positioned according to such characteristics as educational attainment and experience. These characteristics in turn determine the cost (to the employer) of recruiting and training labour in the skills necessary to perform on the job. Therefore, Thurow's job-competition model postulates that the higher a person is in the person queue, the less the cost of recruitment and training and the more likely the person will be to get a job at the head of the job queue (See Fig. 3).

To secure a higher position in the person queue therefore, individuals will continue to invest in education hoping that the additional amount of education will enhance their employability vis-à-vis other competitors in the labour market.In sum, Thurow's job-competition model implies that insofar as job skills requirements is fixed whereas job structure is unresponsive to changes in the relative supply of different skill groups, underutilization of workers' skills (overschooling) will persist. 


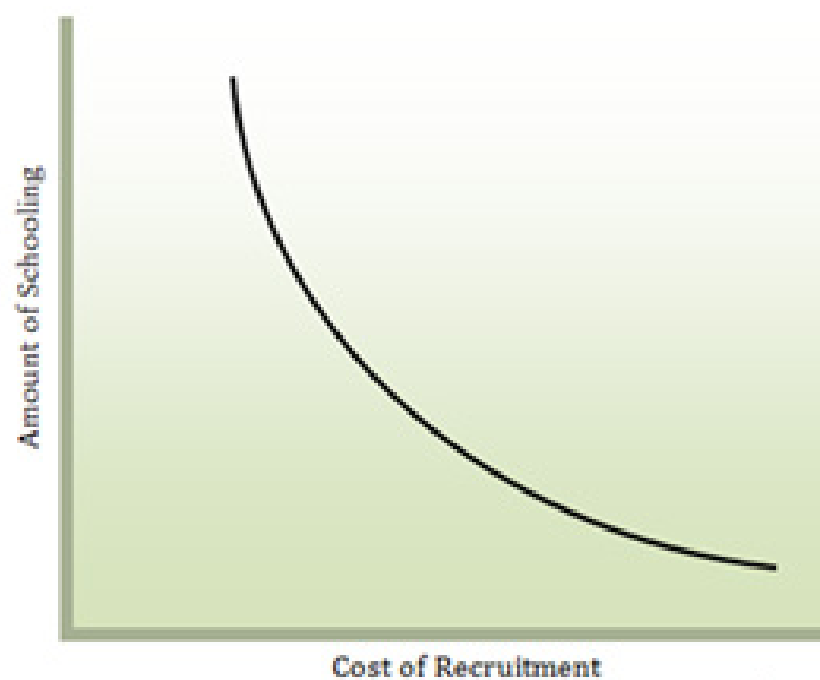

Figure 3. An illustration of Thurow's Job-Competition Model

\subsection{Becker's Human Capital Model}

Gary Becker [4] postulated that individuals will invest in education up to the point where their marginal returns to education are equivalent to their marginal costs. The implications of this human capital model in measuring overschooling is that the single most influential factor, the sole determiner, the only basis for measuring overschooling is the ease with which workers can be matched to jobs, that unless there exists a disequilibrium, one cannot be said to have overschooled (See Fig. 4)

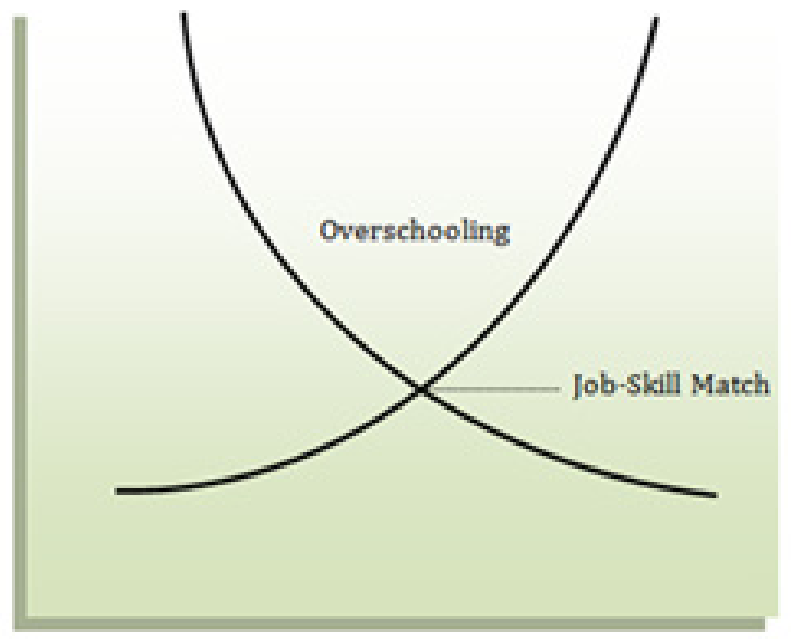

Figure 4. An illustration of the Human Capital Model

In using the foregone models to explain the incidence of overschooling, it is imperative to take cognizance of other significant socioeconomic factors that buttress the supply of educated persons into the labour market. To begin with, the government in recent years have stepped in to subsidize education especially at the primary and secondary levels with a view to comprehensively implementing the current policy on education which prescribes nine years of basic, compulsory and uninterrupted education. In addition, the senior school examination is being subsidized in various states of the federation by both government and nongovernmental organizations. The result is that, with limited/reduced private cost, more persons decide to invest optimally in education. Again, education is often seen as a channel for upward socioeconomic mobility. Persons with more education tend to have better jobs with higher earnings and higher social statuses. Under this guise (social status), most persons, even at advanced age, strive to attain desired educational heights. Also, there is an increased emphasis on certification with attendant rise in the number of persons seeking to acquire educational certificates as well as educational institutions seeking to award such certificates. These factors combine to create a dynamic setting which fosters rising levels of educational attainments which in turn engenders and sustains overschooling.

In sum, the neoclassical economists suggest that overschooling is a short run problem whereas it can be (as researches show) a much longer run problem if the labour market adjusts (as it is doing) more slowly than is assumed in the neoclassical account. Both Spence's job-screening model and Thurow's job-competition model show that overschooling can be a persistent problem insofar as the job structure is unresponsive to changes in the relative supplies of educated workers. The human capital model maintains that unless there exists disequilibrium between acquired schooling and required schooling, one cannot be said to be overschooled. Finally, a number of potent socioeconomic factors (education subsidy and socioeconomic mobility, inter alia) that sustain excess supply of overschooled workers.

\section{Measures of Overschooling: Emerging Issues}

In the literature, overschooling is typically measured by comparing individuals' acquired schooling with occupations' required schooling. However, when it comes to the assessment of what actually amounts to 'required schooling' there are a couple of concerns and considerations that should be addressed. Furthermore, there is also the need to disambiguate 'overschooling' vis-à-vis 'overskilling'. Thus, this section will proceed to discuss contemporary issues in the measurement of overschooling in the light of job requirement and overskilling.

\subsection{Acquired vs. Required Schooling}

When measured using this yardstick, overschooling is seen as the difference between the worker's attained or completed level of schooling and the level of schooling required for the job the worker holds [5]. The implication of this methodology is that required level of schooling must 
necessarily be ascertained before overschooling can be adjudged. Required schooling on the other hand could be measured in either of three different ways.

The first approach involves workers' self-assessment where workers are quizzed about the schooling requirements for their jobs. Issues encountered when using this approach usually arise from variations in the exact phrasing of instrument items and the subjectivity of the worker's self-assessment. According to Hartog [6], respondents may tend to overstate the requirements of their jobs, to upgrade the status of their positions. This tendency may differ between persons doing the same job, and may even systematically differ with attributes that have an impact on wages, such as gender and completed years of schooling. A possible merit of the self-assessment approach is that it is based, hypothetically, on all the relevant information. Contrariwise, workers may be very poorly informed of the potent counterfactuals. Thus it is always good to ask the workers outright whether they are overschooled, underschooled or appropriately schooled for their job $[7,8]$.

The second approach involves job analysis based on information from job descriptions on occupational classifications. A popular example is the Dictionary of Occupational Titles which contains an indicator for the educational requirement in the form of the General Educational Development (GED) Scale. This scale is graduated 1 to 7 , each of the points is translated into school years equivalent -0 to 18 [9]. Appealing though, this approach seems, issues bordering about the currency of job-school requirement information and consensus on the conversion of the GED scale to years of schooling usually arise. Finally, the reliability, validity, and generalizability of this approach is another potent issue that hampers its usability $[10,6]$.

The third approach involves analysis of information based on realized matches [11]. Using this approach, the required amount of schooling is inferred from the mean of completed schooling of all workers holding the same occupation. Verdugo and Verdugo[11] defined occupations at the three digit code. People are then defined to be overschooled or underschooled if their completed level of schooling deviates at least one standard deviation from the mean in their occupation. People that have more/less than this mean are over/underschooled.

Generally, when overschooling is to be measured on the basis of job requirement, the use of the realized matches approach is often regarded as inferior to both the job analysis and the workers self-assessment approaches and is only used if the data do not contain either of the other measures. The reason given for this is that the realized match is the result of demand and supply forces and does not only reflect requirements. Moreover, like the method based on job analysis, it ignores variations in required schooling across jobs within an occupation. Furthermore, the cut-off at one standard deviation from the mean is arbitrary

\subsection{Overskilling vs. Overschooling}

The need to disambiguate overschooling and distinguish it from being overskilled is another prominent issue that deserves attention when measuring overschooling. Various authors have shown concern over the fact that overschooled workers need not be identical with overskilled workers, not any more than they are with adequately matched workers. As a matter of fact, overschooled workers may possess lower/limited skills; thus overschooling does not necessarily mean that the individual is overskilled [12]. In view of this, some approaches have been adopted by researchers to correct the omitted variable bias. A prominent cum promising approach is the instrumental variable approach which exploits exogenous variations in the levels of completed schooling and required schooling to correct or account for the unobserved heterogeneity.

Mention worthy at this point, however, is the fact that finding a credible instrumental variable has hitherto been elusive. However, researchers have constructed measures that attempt to capture in some way, workers excess skills. For example, Chevalier [7] in studying overschooling among university graduates distinguishes two ability levels (clever and underachiever) and three job levels (graduate jobs, non-graduate jobs, and upgraded non-graduate jobs). Based on these delineations, the following allocations are possible: if clever graduates end up in graduate jobs, their match is perfect; if clever graduates end up in upgraded non-graduate jobs, they are genuinely overschooled; if underachievers end up in an upgraded non-graduate job, they are apparently overschooled; if underachievers end up in normal non-graduate jobs, they are genuinely overschooled.

Noteworthy in this methodology is the fact that neither the workers skill level nor whether a non-graduate job has been upgraded is observed. Rather, Chevalier [7] uses information about workers' satisfaction with the match between their work and their qualifications.

In a further attempt to distinguish the overschooled from the overskilled, Chevalier, Green, and McIntosh [13] maintained that a person could only be said to be overskilled if $s /$ he disagrees with the statement that current job offers the opportunity to utilize the knowledge and skills $\mathrm{s} / \mathrm{he}$ has or when the respondent indicated that the current job allows for limited/no use of past experience, skills, and abilities [acquired from schooling]. Although this approach to correcting the issue of unobserved skills heterogeneity promoted by Chevalier, Green, and McIntosh appears very appealing, there is need for caution when adopting it for a study. Primarily because the information they used is based on subjective self-assessments which is prone to measurement error.

In sum, it is clear that the existing approaches to the measure of overschooling are basically data driven with little or no emphasis on technicalities vis-à-vis data capture methodology. Ideally, for measures of overschooling to be universally valid and reliable, there has to be developed a sound theoretical basis for measurement with clarification on the identified conditioning factors, whether such measures 
should be contemporaneous or relative to the life cycle, whether measurement should be made on an ex-ante basis or ex-post basis.

In practice, researchers typically adopt methodologies that either implicitly or explicitly picks on such factors as hiring, standards, performance requirements, relative prices, and so on, to measure overschooling. There is no consensus on which method is to be preferred. Worse still, these different measures correlate negatively highlighting the fact that measurement error is a global issue in contemporary measures of overschooling [5].

\section{Graduate Overschooling in Nigeria}

Without doubt, overschooling is rife in Nigeria as could be discerned from such pointers as employment rates, school enrolments and graduation, and per capita income estimates. Several reports have shown a rapid increase in tertiary education enrolment. Nigeria possesses the largest university system in Sub-Saharan Africa. Nigeria's entire tertiary education system (Federal, State and Private) comprises 220 institutions with 48 state and federal universities enrolling over 400,000 students. Enrolments in the Federal Universities grew at the rapid rate of $12 \%$ annually during the 1990s and totalled 325,299 students by 2000 (NUC, 2002). In comparison, state university enrolments totalled 104,776 in $1997 / 98$, accounting for $28 \%$ of Nigeria's total university enrolments in that year [14].

Surprisingly though, there has been a steady decline in the rate of graduate employment for reasons ranging from paucity of employment opportunities to increased un-employability of university graduates. The incidence of graduate overschooling is occasioned by the large expansion in the supply of graduates over a short period of time without commensurate absorption of these graduates by the labour market. It therefore betrays disequilibrium in the demand and supply of labour in the short run.

Public and private employers of University graduates, as well as the government itself, consider the quality of university graduates to be inadequate. A study of the labour market for graduates found that employers believe 'university graduates are poorly trained and unproductive on the job, ...and shortcomings are particularly severe in oral and written communication, and in applied technical skills' [15]. Labour market demand for degree-based professional skills over the period 1991 - 1999 centred largely in engineering, business administration, health services, accounting and marketing [16]. During the same period, however, $49 \%$ of the supply of graduates produced by Federal Universities was concentrated in Arts, Education, Law and Social Sciences. Such mismatch engenders overschooling. Under these conditions, the labour market annually absorbed just $10 \%$ of all graduates produced by the entire education system [16]. University graduates unemployment was estimated to be $22 \%$ in 1998 [15].

Such findings suggest the need for adaptive university responses vis-à-vis the labour market for public and private employment. As one African observer has noted, "The supply of education services is market blind. Admission policies of higher education institutions are neither related to labour demand requirements, nor to individual student interests, but mainly to secondary school grades" [17]. Elsewhere in the world, emerging institutional adaptations to the problem of labour market mismatch include the formation of "knowledge coalitions" with other knowledge producing centres in society [18], the establishment of more effective labour market information systems linked to career counselling in universities, and greater private sector involvement in curriculum consultations, faculty attachments, student placements, and research funding [17].

Furthermore, some studies have shown that the training which tertiary education students in Nigeria receive have not been fully successful in equipping them with desirable skills and competencies required for job creation and self-employment [19-21].

\section{Conclusion}

Globally, there is the incidence of overschooling with attendant implications to national economy and productivity. A major setback in the study of overschooling has hitherto been measurement issues-concerns about measurement methodology and variable heterogeneity. So far, several approaches have been created and used, but there appears to be no consensus on the approach to be preferred as each of the various existing approaches has a measure of weakness. Due to the implications of overschooling to national economy, productivity, and social health as exposed by scores of researches, it is imperative that an empirical and comprehensive assessment of overschooling be embarked upon with a view to discovering ways to achieve, locally, the needed labour demand-supply equilibrium in the short run.

\section{Recommendations}

Based on the discourse here presented, the authors advance the following recommendations:

a. There should be a reinforcement of the education-economics interrelations with the prospect of pulling together intellectual and material resources to embark on an in-depth study and analysis of trends in overschooling at all levels of education.

b. Education economists should research and invent sound theories that will enhance an understanding of the causes and effects of overschooling.

c. Psychometrists, psychologists, educators, economists, and experts in measurement and evaluation should gang up through conferences and committees to study and draw up valid and reliable yard sticks for measuring overschooling. 
d. The government and her policy making institutions should formulate wage policies and employment strategies that will assuage the labour-wage and labour demand - supply disequilibria which are major sustainers of incessant cases of industrial activities in countries like Nigeria.

e. Acquisition of educational certificates should be deemphasized whilst renewed emphasis should be placed on vocational and entrepreneurial education. It is believed that if Nigerians are reoriented from job seekers to job creators, the incidence of overschooling will be curtailed in the short run as persons seeking education will also seek to acquire only the kind and amount of schooling required for the kind of job he desires to create.

f. Government at all levels should put in place appropriate machinery by way of economic grants, loan facilities, incentives and vocational subsidies, to encourage entrepreneurship and not just continue to subsidize general education.

g. Institutions of learning should endeavour to focus more on helping their entrants acquire skills-based training and entrepreneurship capacities through the provision and use of required teaching-learning facilities, design and implementation of psycho-academic programmes with emphasis on career education and career counselling. This implies that schools should employ adequate numbers of counselling psychologists and psychologists and facilitate the discharge their services in the school system to the betterment of student's vocational development.

h. Finally, researchers from relevant fields should pick up their different research apparatus and proceed with an investigation into the psychological, sociological, and economic variables that spawn overschooling and allied phenomena. This will provide professional literacy on the state and dynamics of the overschooling phenomenon. Such an exposé will be invaluable to policy makers, employers of labour, academics, and education investors.

\section{REFERENCES}

[1] Rumberger, R. (1987). The impact of surplus schooling on productivity and earnings. Journal of Human Resources. $24-50$.

[2] Spence, M. (1973). Job market signalling. Quarterly Journal of Economics, 87:355-374.

[3] Thurow, L. (1975). Generating inequality. Basic Books.

[4] Becker, Gary S. (1964). Human Capital. New York: NBER.

[5] Leuven, E. \&Oosterbeek, H. (2011). Overeducation and Mismatch in the Labour Market. IZA Discussion Paper No.
5523.

[6] Hartog, J. (2000) Overeducation and earnings: where we are and where we should go. Economics of Education Review, 19 (2), 131-147.

[7] Chevalier, A. (2003). Measuring over-education. Economica, 70(279), 509-531.

[8] Verhaest, D. \&Omey, E. (2006). The impact of overeducation and its measurement. Social Indicators Research, 77(3):419-448.

[9] Eckaus, R. (1964). Economic criteria for education and training. Review of Economics and Statistics, 46:181-190.

[10] Halaby, C. (1994). Overeducation and Skill Mismatch. Sociology of Education, 67, 47-59.

[11] Verdugo, R.\&Verdugo, N. (1989), The impact of surplus schooling on earnings: some additional findings. Journal of Human Resources, 24, 629-643.

[12] Allen, J. \& R. van der Velden (2001). Educational Mismatches versus Skill Mismatches: Effects on Wages, Job satisfaction, and on-the-job search. Oxford Economic Papers 53 (3), 434-452.

[13] Green, F.\& McIntosh, S. (2007), Is there a genuine under-utilization of skills among the over-qualified? Applied Economics, 39, 427-439.

[14] National Universities Commission. (2002). Academic staffing profiles, student enrolment, dropout and graduation rates at Nigerian universities during 1995/96 to 1999/2000 academic years. Unpublished. Abuja: Department of Academic Planning, National Universities Commission.

[15] Dabalen, A. Oni, B. \&Adekola, O. (2000). Labour Market Prospects of University Graduates in Nigerian. Background study conducted to inform the design of the Nigeria University System Innovation Project.

[16] Oni, B. 2000. "The Demand for University Graduates and Employers' Assessment of Graduate Skills in Nigeria." Draft. Ibadan: NISER.

[17] Boateng, K. (2002). Higher education and the labour market: A logical framework for policymakers in Africa's education sector. Draft. Addis Ababa: Economic Commission for Africa.

[18] Clark, B. (2001). The Entrepreneurial University: New Foundations for Colleagiality, Autonomy and Achievement. Higher Education Management, 13:2, 9-24.

[19] Amaewhule, W. A. (2007). Education, the world of work and the challenge of change: In search of intervention strategies. Inaugural lecture series No. 23; River State University of Science and Technology, Nkpolu Port Harcourt.

[20] Madumere-Obike, C. U. (2000). Reposition Education for Employment: Implications for educational management. Multidisciplinary Journal of Research Development (MIKJORED). 7(3) 43-52.

[21] Nwangwu I. O. (2007). Entrepreneurship in Education. Concept and Constraints. African Journal of Education and Developmental Studies 4(1), 196 - 207. 